\title{
Interleukin-10-producing $\mathrm{LAG}^{+}$regulatory $T$ cells are associated with disease activity and abatacept treatment in rheumatoid arthritis
}

Shinichiro Nakachi', Shuji Sumitomo ${ }^{1}$, Yumi Tsuchida ${ }^{1}$, Haruka Tsuchiya ${ }^{1}$, Masanori Kono ${ }^{1}$, Rika Kato', Keiichi Sakurai ${ }^{1}$, Norio Hanata ${ }^{1}$, Yasuo Nagafuchi ${ }^{1}$, Shoko Tateishi ${ }^{1,2}$, Hiroko Kanda ${ }^{1,2}$, Tomohisa Okamura ${ }^{1,3}$, Kazuhiko Yamamoto ${ }^{1}$ and Keishi Fujio ${ }^{{ }^{*}}$

\begin{abstract}
Background: Regulatory T cells (Tregs) play a role in the suppression of inflammation in autoimmune diseases, and lymphocyte activation gene 3 (LAG3) was reported as a marker of interleukin (IL)-10-producing Tregs. We aimed to clarify the function of human IL-10-producing $C D 4^{+} C D 25^{-} \mathrm{LAG} 3^{+} \mathrm{T}$ cells ( $\mathrm{LAG} 3^{+}$Tregs) and their association with rheumatoid arthritis (RA).

Methods: $\mathrm{LAG3}^{+}$Tregs of human peripheral blood mononuclear cells (PBMCs) were cultured with B cells and follicular helper $T$ cells to examine antibody suppression effects. The frequency of LAG3 ${ }^{+}$Tregs was evaluated in peripheral blood samples from 101 healthy donors and 85 patients with RA. In patients treated with abatacept, PBMC samples were analyzed before and after treatment. Naive $\mathrm{CD}^{+} \mathrm{T}$ cells were sorted and cultured in the presence of abatacept, followed by flow cytometric analysis and function assays.

Results: $L A G 3^{+}$Tregs produced high amounts of IL-10 and interferon- $\gamma$, and they suppressed B-cell antibody production more strongly than $\mathrm{CD} 25^{+}$Tregs. Cell-to-cell contact was required for the suppressive function of $\mathrm{LAG}^{+}$Tregs. The frequency of $\mathrm{LAG}^{+}$Tregs was lower in patients with RA, especially those with higher Clinical Disease Activity Index scores. LAG3 ${ }^{+}$Tregs significantly increased after 6 months of abatacept treatment, whereas $\mathrm{CD} 25^{+}$Tregs generally decreased. Abatacept treatment in vitro conferred LAG3 and EGR2 expression on naive $\mathrm{CD}^{+} \mathrm{T}$ cells, and abatacept-treated $\mathrm{CD} 4^{+} \mathrm{T}$ cells exhibited suppressive activity.

Conclusions: IL-10-producing LAG3 ${ }^{+}$Tregs are associated with the immunopathology and therapeutic response in RA. LAG3 ${ }^{+}$Tregs may participate in a mechanism for the anti-inflammatory and immune-modulating effects of targeted therapy for costimulation.
\end{abstract}

Keywords: LAG3, Regulatory T cell, IL-10, Abatacept, Rheumatoid arthritis, Antibody production

\footnotetext{
* Correspondence: kfujio-tky@umin.ac.jp

${ }^{1}$ Department of Allergy and Rheumatology, Graduate School of Medicine,

the University of Tokyo, 7-3-1 Hongo, Bunkyo-ku, Tokyo 113-8655, Japan

Full list of author information is available at the end of the article
} 


\section{Background}

Rheumatoid arthritis (RA) is the most common type of autoimmune disease. It is characterized by synovial inflammation, production of autoantibodies including anticitrullinated protein antibody (ACPA), and destruction of cartilage and bone. With regard to the pathogenesis of RA, dendritic cells and macrophages are initially activated, and they present autoantigens to T cells, leading to the expansion of autoreactive T cells [1]. Autoreactive B cells also play a central role through their differentiation into long-lived memory $\mathrm{B}$ cells and autoantibodyproducing plasma cells [2]. Activation of autoreactive T cells and B cells further stimulates macrophages to produce proinflammatory cytokines such as tumor necrosis factor$\alpha$, interleukin (IL)-1 $\beta$, and IL-6. Therefore, adaptive immunity mediated by autoreactive $\mathrm{T}$ cells and $\mathrm{B}$ cells can be one of the most important targets in the therapy of RA [3].

Regulatory $\mathrm{T}$ cells (Tregs) constitute a subpopulation of $\mathrm{T}$ cells that plays an indispensable role in maintaining tolerance to self-antigens and immunological homeostasis. A lack of Tregs or their dysfunction leads to a breakdown of immunological tolerance to self-antigens and can result in autoimmune diseases [4, 5]. A number of Treg subsets have been identified over the years [6-10], and cluster of differentiation $\mathrm{CD} 4{ }^{+} \mathrm{CD} 25^{+} \mathrm{FOXP} 3^{+}$regulatory $\mathrm{T}$ cells $\left(\mathrm{CD} 25^{+}\right.$Treg) [6] and $\mathrm{CD}^{+}{ }^{+}$IL-10-producing regulatory T cells (IL-10-producing Tregs) [7] are the best characterized among them.

CD25 ${ }^{+}$Tregs develop mainly in the thymus to specifically express the Forkhead box P3 (Foxp3) gene [11]. Scurfy mice, which have a frameshift mutation in the Foxp3 gene, exhibit severe inflammatory infiltration of the skin and liver [12]. However, many organs, including the central nervous system, joints, and small intestine, remain unaffected in scurfy mice [13]. These results suggest the existence of additional important mechanisms other than CD25 ${ }^{+}$Tregs that support self-tolerance against many organs including joints [14].

IL-10-producing Tregs are characterized by the production of high amounts of IL-10 without FOXP3 expression. IL-10-producing Tregs have been reported to ameliorate experimental autoimmune encephalitis [15] and colitis [7] in mouse models. Thus far, IL-10producing Tregs have primarily been reported as induced populations in the presence of vitamin $D_{3}[16]$, anti-CD46 antibody [17], rapamycin [18], or IL-27 [19, 20]. This is due in part to the difficulty in identifying naturally occurring IL-10-producing Tregs because of the lack of definitive surface markers. However, recent reports have shown that lymphocyte activation gene 3 (LAG3) protein, a major histocompatibility complex class II-binding CD4 homologue, is expressed on IL-10producing $\mathrm{CD}^{+} \mathrm{T}$ cells and is a candidate phenotypic surface marker for IL-10-producing Tregs [21-23].
We have previously identified murine $\mathrm{CD} 44^{+} \mathrm{CD} 25^{-}$ $\mathrm{LAG}^{+}$regulatory $\mathrm{T}$ cells that produce high amounts of IL-10 and interferon (IFN)- $\gamma$, lack Foxp3 expression, and suppress B-cell antibody production [21, 23]. They are regulated by early growth response gene 2 (Egr2), which is important for the maintenance of T-cell anergy by negatively regulating $\mathrm{T}$-cell activation [24]. We therefore hypothesized that human $\mathrm{CD} 4^{+} \mathrm{CD} 25^{-} \mathrm{LAG} 3^{+} \mathrm{T}$ cells might have the same functions as those in mice and that they might be associated with human autoimmune diseases. We aimed to characterize $\mathrm{CD} 4{ }^{+} \mathrm{CD} 25^{-} \mathrm{LAG}^{+} \mathrm{T}$ cells in healthy and autoimmune states and to determine the impact of abatacept treatment that targets T-cell responses.

\section{Methods}

\section{Blood samples and clinical data}

All clinical investigations conformed to the Declaration of Helsinki principles and were approved (10154 and G3582) by the ethics committee of the University of Tokyo. Peripheral blood mononuclear cells (PBMCs) were obtained from 101 self-reported screened healthy donors and 85 patients with RA who fulfilled the 1987 American College of Rheumatology revised criteria or the 2010 American College of Rheumatology/European League Against Rheumatism classification criteria. Moreover, PBMCs were taken from four healthy donors vaccinated with a seasonal inactivated influenza virus in 2013. Clinical characteristics and laboratory data were documented on the day of sample collection. All subjects provided written informed consent.

\section{Cell isolation and flow cytometry}

PBMCs were isolated from whole blood by Ficoll-Paque Plus (GE Healthcare Life Sciences, Pittsburgh, PA, USA) gradient separation. Fc receptor binding inhibitor (eBioscience, San Diego, CA, USA) was added to the isolated PBMCs. They were stained with the following monoclonal antibodies (mAbs) for 20 minutes: Alexa Fluor 488 anti-C-X-C chemokine receptor type 5 (antiCXCR5; RF8B2), phycoerythrin (PE) anti-C-C chemokine receptor type 6 (anti-CCR6; 11A9), Brilliant Violet 412 anti-CXCR3 (1C6), and V500 anti-CD4 (RPA-T4) from BD Biosciences (San Jose, CA, USA); Alexa Fluor 488 anti-CD49b (AK7), peridinin-chlorophyll protein (PerCP)-Cy5.5 anti-CD3 (UCHT1), PerCP-Cy5.5 antiCCR7 (G043H7), allophycocyanin anti-CD19 (HIB19), allophycocyanin-Cy7 anti-CD45RA (HI100), and Brilliant Violet 421 anti-CD25 (BC96) from BioLegend (San Diego, CA, USA); PE-Cy7 anti-CD127 (eBioRDR5) from eBioscience; and PE anti-LAG3 polyclonal antibody (FAB2319P, 4:100) from R\&D Systems (Minneapolis, MN, USA). All cell subsets were analyzed and sorted by eight-color MoFlo XDP (Beckman Coulter Life Sciences, Indianapolis, IN, USA). Each subset was defined as 
having the following immunophenotype: naive $\mathrm{CD} 4^{+} \mathrm{T}$ cells were $\mathrm{CD} 4^{+} \mathrm{CD} 45 \mathrm{RA}^{+} \mathrm{CD} 25^{-} \mathrm{LAG}^{-} \mathrm{CCR}^{+}$(Fig. 1) or $\mathrm{CD}^{+} \mathrm{CD} 45 \mathrm{RA}^{+}$(Fig. 4); follicular helper $\mathrm{T}\left(\mathrm{T}_{\mathrm{FH}}\right)$ cells were $\mathrm{CD} 44^{+} \mathrm{CD} 45 \mathrm{RA}^{-} \mathrm{CXCR} 5^{+} \mathrm{CD} 25^{-} \mathrm{LAG}^{-}$; $\mathrm{CD} 25^{+}$Tregs were $\mathrm{CD}^{+} \mathrm{CD} 45 \mathrm{RA}^{-} \mathrm{CD} 25^{+} \mathrm{LAG}^{-} \mathrm{CD} 127^{\mathrm{dim}}$; type 1 helper $\mathrm{T}$ (Th1) cells were $\mathrm{CD} 4^{+} \mathrm{CD} 45 \mathrm{RA}^{-} \mathrm{CXCR} 3^{+} \mathrm{CCR}^{-}$; Th2 cells were $\mathrm{CD} 4^{+} \mathrm{CD} 45 \mathrm{RA}^{-} \mathrm{CXCR}^{-}{ }^{-} \mathrm{CR} 6^{-}$; Th17 cells were $\mathrm{CD}^{+}{ }^{+} \mathrm{CD} 45 \mathrm{RA}^{-}{ }^{-} \mathrm{CXCR} 3^{-} \mathrm{CCR}^{+}{ }^{+}$; $\mathrm{LAG}^{+}$Tregs were $\mathrm{CD} 4^{+} \mathrm{CD} 45 \mathrm{RA}^{-} \mathrm{CD} 25^{-} \mathrm{LAG}^{+}$; and $\mathrm{B}$ cells were $\mathrm{CD}^{-} \mathrm{CD} 19^{+}$. Data were analyzed using FlowJo software (FlowJo, Ashland, OR, USA).

\section{Measurement of cytokines by enzyme-linked immunosorbent assay}

$\mathrm{CD}^{+} \mathrm{T}$ cells $\left(2 \times 10^{4}\right.$ cells/well $)$ were stimulated with plate-bound anti-CD3 mAb $(5.0 \mu \mathrm{g} / \mathrm{ml}, \mathrm{UCHT} 1 ; \mathrm{R} \& \mathrm{D}$ Systems) and anti-CD28 mAb $(1.0 \mu \mathrm{g} / \mathrm{ml}, 37407 ; \mathrm{R} \& \mathrm{D}$ Systems) in flat-bottomed 96-well plates for 3 days. Concentrations of IL-10, IFN- $\gamma$, and IL-17A in the supernatants were measured using enzyme-linked immunosorbent assay (ELISA) kits according to the manufacturer's protocol (OptEIA Human IL-10 ELISA Kit II; BD Biosciences; Human IFN- $\gamma$ ELISA Ready-SET-Go! and Human IL-17A ELISA Ready-SET-Go!; eBioscience). Cells were cultured in Gibco RPMI 1640 medium (Invitrogen, Paisley, UK) supplemented with 10\% FBS (Equitech-Bio, Kerrville, TX, USA), $100 \mu \mathrm{g} / \mathrm{ml} \mathrm{L}$-glutamine, $100 \mathrm{U} / \mathrm{ml}$ penicillin, $100 \mu \mathrm{g} / \mathrm{ml}$ streptomycin, and $50 \mu \mathrm{M} 2$-mercaptoethanol (Life Technologies, Carlsbad, CA, USA).

\section{B-cell and T-cell coculture}

Each $\mathrm{CD}^{+} \mathrm{T}$ cell subset $\left(1 \times 10^{5}\right.$ cells/well $)$ was cocultured with $\mathrm{B}$ cells $\left(1 \times 10^{5}\right.$ cells/well $)$ and $\mathrm{T}_{\mathrm{FH}}$ cells $(5 \times$ $10^{4}$ cells/well) in round-bottomed 96 -well plates. Recombinant staphylococcal enterotoxin B (SEB) $(2 \mu \mathrm{g} /$ ml; Toxin Technology, Sarasota, FL, USA) was added to stimulate B cells. Blocking antihuman IL-10 mAb (25209; R\&D Systems), blocking antihuman Fas ligand mAb (100410; R\&D Systems), or mouse immunoglobulin

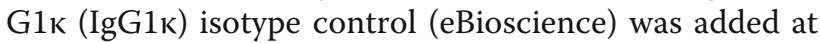
a concentration of $10 \mu \mathrm{g} / \mathrm{ml}$ on the first day of the coculture in the same experimental system as above. To assess cell-cell contact, a coculture experiment was performed using a Transwell plate (HTS Transwell-96 System [3381]; Corning Life Sciences, Acton, MA, USA) with the following cells: $\mathrm{B}$ cells, $3 \times 10^{5}$ cells/well; $\mathrm{T}_{\mathrm{FH}}$ cells, $2 \times 10^{5}$ cells/well; and $\mathrm{CD}_{4}{ }^{+} \mathrm{CD} 25^{-} \mathrm{LAG}^{+} \mathrm{CD} 45 \mathrm{RA}^{-} \mathrm{T}$ cells, $1 \times$ $10^{5}$ cells/well. The concentrations of IgG, IgA, and IgM in

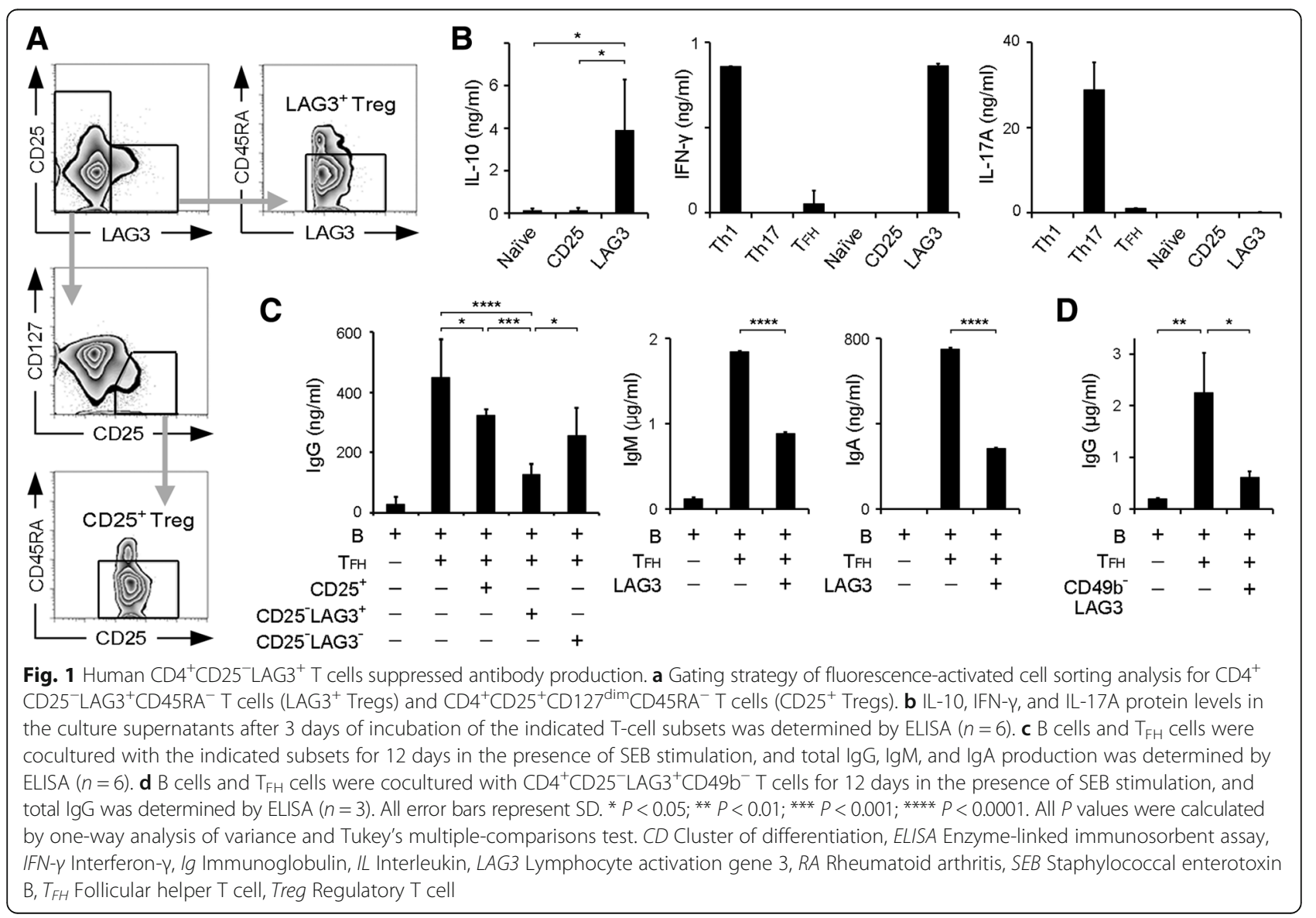


the 12-day culture supernatant were measured by ELISA (Human IgG ELISA Quantitation Set, Human IgA ELISA Quantitation Set, and Human IgM ELISA Quantitation Set; Bethyl Laboratories, Montgomery, TX, USA).

\section{Culture in the presence of abatacept}

Antigen-presenting cells (APCs) were sorted as $\mathrm{CD}^{-}$ cells and irradiated with $30 \mathrm{~Gy}$. Abatacept was purchased from Bristol-Myers Squibb (Princeton, NJ, USA) and used at a final concentration of $10 \mu \mathrm{g} / \mathrm{ml}$. Human IgG1 Fc (R\&D Systems) was added as a control. Cultured cells were analyzed and sorted as 7-amino actinomycin D (7-AAD)-negative cells at day 4 (BioLegend). Sorted 7-AAD-negative $\mathrm{CD}^{+} \mathrm{T}$ cells were cultured with $B$ cells and $\mathrm{T}_{\mathrm{FH}}$ cells in the aforementioned system to investigate the suppressive function of the cells induced by abatacept.

\section{Quantitative real-time polymerase chain reaction}

Total RNA was isolated using RNeasy Micro Kit (QIAGEN, Valencia, CA, USA) according to the manufacturer's protocol. Complementary DNA was synthesized with SuperScript III Reverse Transcriptase (Life Technologies) and oligo(dT) primers, and it was mixed with SYBR Green Master Mix (Life Technologies). The real-time polymerase chain reaction (PCR) primer pairs were as follows: human EGR2 sense: 5'-TGGAGAGAAGAGG TCGTTGG-3' and antisense: 5' -CTGGATGAGGCTGT GGTTG-3'; FAS sense: 5'-TGCAGAAGATGTAGATT GTGTGATGA-3' and antisense: 5'-GGGTCCGGGTG CAGTTTATT-3', and CD247 sense: 5'-GGGAGAATG ATGGATGTGAA-3' and antisense: 5'-CCGATGAA CCCCTAAACCA-3'. Quantitative PCR was conducted using an iCycler PCR system (Bio-Rad Laboratories, Hercules, CA, USA). The expression of each gene was normalized to the glyceraldehyde 3-phosphate dehydrogenase housekeeping gene (GAPDH) (forward: 5'-GAAGGTGAAGGTCGGAGTC-3' and reverse: 5' GAAGATGGTGATGGGATTTC-3').

\section{Statistical analysis}

Data are presented as mean \pm SD. Statistical differences between groups were evaluated using an unpaired two-tailed Student's $t$ test, the Mann-Whitney $U$ test, or the Wilcoxon signed-rank test for comparing two groups, and one-way analysis of variance or the Kruskal-Wallis test was used to compared three or more groups. $P$ values less than 0.05 were considered statistically significant $(* P<0.05 ; * * P<0.01 ; * * * P<$ 0.001 ; $* * * 0.0001)$. Calculations were conducted using Prism version 5.03 software (GraphPad Software Inc., La Jolla, CA, USA). To compare the frequency of Tregs in patients, a statistical analysis was conducted using $\mathrm{R}$ version 3.1.2 software ( $\mathrm{R}$ Foundation for Statistical Computing, Vienna, Austria).

\section{Results \\ Human $\mathrm{CD}^{+}{ }^{+} \mathrm{CD} 25^{-} \mathrm{LAG}^{+}{ }^{+} \mathrm{CD} 45 \mathrm{RA}^{-} \mathrm{T}$ cells produce IL-10 and suppress antibody production}

In human PBMCs, we identified $\mathrm{CD} 4^{+} \mathrm{CD} 25^{-} \mathrm{LAG}^{+} \mathrm{T}$ cells that were negative for Foxp3. Confirmation of Foxp3 expression and suppressive activity of control $\mathrm{CD} 4{ }^{+} \mathrm{CD} 25^{+}$Tregs indicated the adequacy of gating strategies (Fig. 1a and Additional file 1: Figures S1 and S2). Upon T-cell receptor (TCR) stimulation, $\mathrm{CD} 4^{+} \mathrm{CD} 25^{-}$ LAG3 $^{+}$T cells produced high amounts of IL-10, amounts of IFN- $\gamma$ as much as Th1 cells, and no IL-17A (Fig. 1b), consistent with the results for murine $\mathrm{CD} 4{ }^{+} \mathrm{CD} 25^{-} \mathrm{LAG}^{+}$ Tregs [21]. Intracellular staining revealed that more $\mathrm{LAG}^{+} \mathrm{T}$ cells (mean 14.2\%) expressed IL-10 than naive $\mathrm{CD}^{+}{ }^{+} \mathrm{T}$ cells (mean 4.8\%) (Additional file 1: Figure S3). Given that murine $\mathrm{CD} 4{ }^{+} \mathrm{CD} 25^{-} \mathrm{LAG}^{+}$Tregs efficiently control B-cell functions, we cocultured these cells with $B$ cells and $T_{F H}$ cells and measured IgG in the supernatants. When SEB was used to imitate the antigen-specific interaction between $\mathrm{B}$ cells and $\mathrm{T}_{\mathrm{FH}}$ cells, we found that $\mathrm{CD}^{+}{ }^{+} \mathrm{CD} 25^{-} \mathrm{LAG}^{+} \mathrm{T}$ cells significantly suppressed IgG production by $\mathrm{B}$ cells (Fig. 1c). Moreover, $\mathrm{CD} 4^{+} \mathrm{CD} 25^{-}$ $\mathrm{LAG}^{+} \mathrm{T}$ cells also suppressed IgM and IgA (Fig. 1c), which indicated that $\mathrm{CD} 4^{+} \mathrm{CD} 25^{-} \mathrm{LAG}^{+} \mathrm{T}$ cells inhibited immunoglobulin production instead of inhibiting class switching. In a previous study, $\mathrm{LAG} 3^{+} \mathrm{CD} 49 \mathrm{~b}^{+} \mathrm{T}$ cells were reported to have the suppressive function of $\mathrm{T}$ cells among IL-10-producing Tregs [22]. Therefore, we assessed whether $\mathrm{CD} 49 \mathrm{~b}$ was required for antibody suppression by $\mathrm{CD}^{+} \mathrm{CD} 25^{-} \mathrm{LAG}^{+} \mathrm{T}$ cells and found that $\mathrm{CD} 49 \mathrm{~b}^{-} \mathrm{CD} 4^{+}$ $\mathrm{CD}_{25}$ LAG $^{+} \mathrm{T}$ cells significantly suppressed antibody production (Fig. 1d). Taken together, these results showed that $\mathrm{CD}^{+} \mathrm{CD}^{2} 5^{-} \mathrm{LAG}^{+} \mathrm{T}$ cells in human PBMCs produced high levels of IL-10 and suppressed B-cell antibody production, regardless of CD49b expression.

\section{The suppressive function of $\mathrm{CD} 4^{+} \mathrm{CD} 25^{-} \mathrm{LAG}^{+} \mathrm{T}$ cells requires cell-to-cell contact}

We conducted experiments using Transwell plates and found that the suppressive function of $\mathrm{CD} 4^{+} \mathrm{CD} 25^{-}$ $\mathrm{LAG}^{+} \mathrm{T}$ cells was abrogated in the absence of direct contact with $\mathrm{B}$ cells or $\mathrm{T}_{\mathrm{FH}}$ cells (Fig. 2a). Among interactions between cell surface molecules, Fas-Fas ligand interaction is associated with antibody suppression of murine LAG3 $^{+}$Tregs [23]. In a blocking experiment, the addition of anti-Fas ligand antibody abrogated the suppressive function of these cells, whereas anti-IL-10 antibody did not affect this suppression (Fig. 2b). This suggests that $\mathrm{CD} 4{ }^{+} \mathrm{CD} 25^{-} \mathrm{LAG}^{+} \mathrm{T}$ cells exerted their suppressive function in a manner requiring Fas-Fas ligand interaction rather than IL-10. 

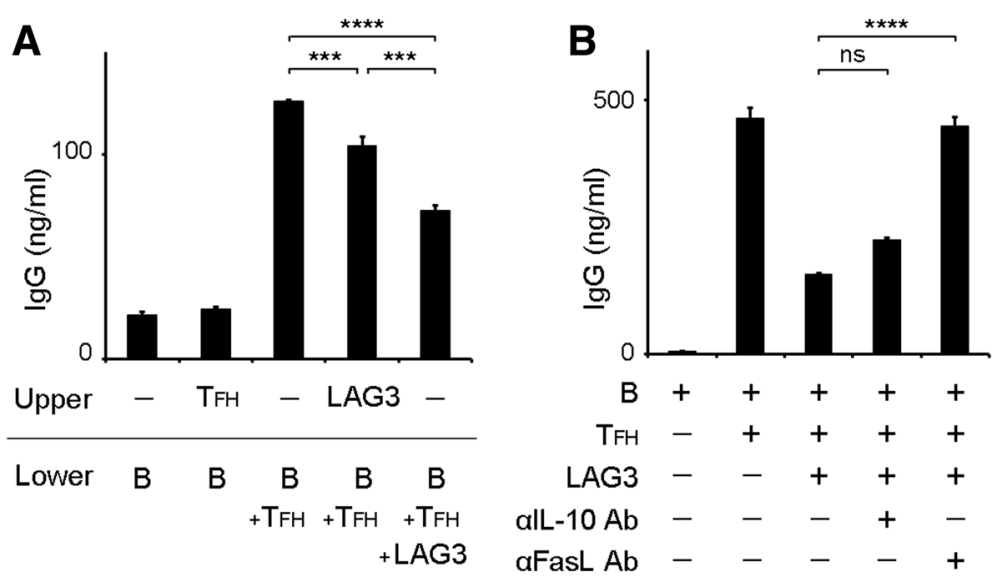

Fig. $2 \mathrm{LAG} 3^{+}$Tregs suppressed B-cell antibody production independent of IL-10. a B cells and $T_{F H}$ cells were cocultured with $L A G 3^{+}$Tregs under staphylococcal enterotoxin B stimulation in Transwells for 12 days. The indicated subsets were placed in upper and lower chambers as described. Total IgG production was determined by ELISA $(n=3)$. b Anti-IL-10 antibody and anti-FasL antibody were added to the same coculture system as in (a). Total IgG production was determined by ELISA $(n=3)$. All error bars represent SD. ${ }^{* *} P<0.001 ; *^{* * *} P<0.0001$. All $P$ values were calculated by one-way analysis of variance and Tukey's multiple-comparison test. Ab Antibody, ELISA Enzyme-linked immunosorbent assay, FasL Fas ligand, 19 Immunoglobulin, IL Interleukin, LAG3 Lymphocyte activation gene 3, $T_{F H}$ Follicular helper T cell, Treg Regulatory T cell

The frequency of $\mathrm{LAG}^{+}$Tregs was decreased in patients with rheumatoid arthritis and significantly increased with abatacept treatment

We analyzed 101 healthy subjects and 85 patients with RA to assess $\mathrm{LAG}^{+}$Treg frequency (Table 1). The frequency of $\mathrm{LAG}^{+}$Tregs was significantly lower in patients with RA than in healthy donors $(3.76 \pm 2.72 \%$ in RA vs $5.07 \pm 2.78 \%$ in healthy donors, $P<0.001$ ) (Fig. $3 a$ ). Moreover, the frequency of $\mathrm{LAG}^{+}$Tregs in untreated patients with RA was significantly lower than that of healthy donors $(P<0.05)$ (Fig. 3b). Whereas the frequency of CD25 $5^{+}$Tregs in patients with RA was significantly lower than that in healthy donors $(P<0.05)$ (Fig. 3a), in the patients with untreated RA, the frequency of $\mathrm{CD}_{25} 5^{+}$Tregs was not different from that in healthy donors (Fig. 3b). Moreover, LAG3 ${ }^{+}$Tregs demonstrated a significant decrease in patients with higher disease activity $(P<0.05)$ (Fig. 3c), whereas the frequencies of $\mathrm{CD}^{2} 5^{+}$Tregs were similar regardless of disease states. However, there were not significant correlations

Table 1 Baseline demographics and clinical characteristics

\begin{tabular}{llll}
\hline & RA $(n=85)$ & Naive RA $(n=16)$ & RA before abatacept $(n=18)$ \\
\hline Female sex, $n(\%)$ & $67(79)$ & $10(63)$ & $15(83)$ \\
Age, years & $58.9(13.1)$ & $55.9(12.2)$ & $62.7(13.2)$ \\
Disease duration, months & $139.4(153.9)$ & $6.7(8.3)$ & $187.5(144.2)$ \\
DAS28-CRP & $3.7(1.5)$ & $4.1(1.6)$ & $4.2(1.3)$ \\
DAS28-ESR & $4.4(1.6)$ & $4.9(1.6)$ & $4.9(1.2)$ \\
CDAl & $16.6(12.1)$ & $21.6(14.5)$ & $21.4(11.7)$ \\
Rheumatoid factor, \% positive & $74(87)$ & $15(94)$ & $15(83)$ \\
Anti-CCP antibody, \% positive & $72(85)$ & $13(81)$ & $18(100)$ \\
Levels of CRP, mg/dl & $1.81(3.24)$ & $3.40(5.30)$ & $1.54(2.85)$ \\
Treatment naive, $n$ (\%) & $16(19)$ & $16(100)$ & $0(0)$ \\
Treatment with MTX, $n$ (\%) & $41(48)$ & $0(0)$ & $10(56)$ \\
Treatment with biologics, $n(\%)$ & $19(22)$ & $0(0)$ & $5(28)$ \\
TNF-a inhibitor & $8(9)$ & $0(0)$ & $3(17)$ \\
Tocilizumab & $5(6)$ & $0(0)$ & $2(11)$ \\
Abatacept & $6(7)$ & $0(0)$ & $0(0)$
\end{tabular}

Abbreviations: RA Rheumatoid arthritis, DAS28 Disease Activity Score in 28 joints, CRP C-reactive protein, ESR Erythrocyte sedimentation rate, CDAI Clinical Disease Activity Index, CCP Cyclic citrullinated peptide, MTX Methotrexate, TNF Tumor necrosis factor Data are presented as mean (SD), unless otherwise specified 

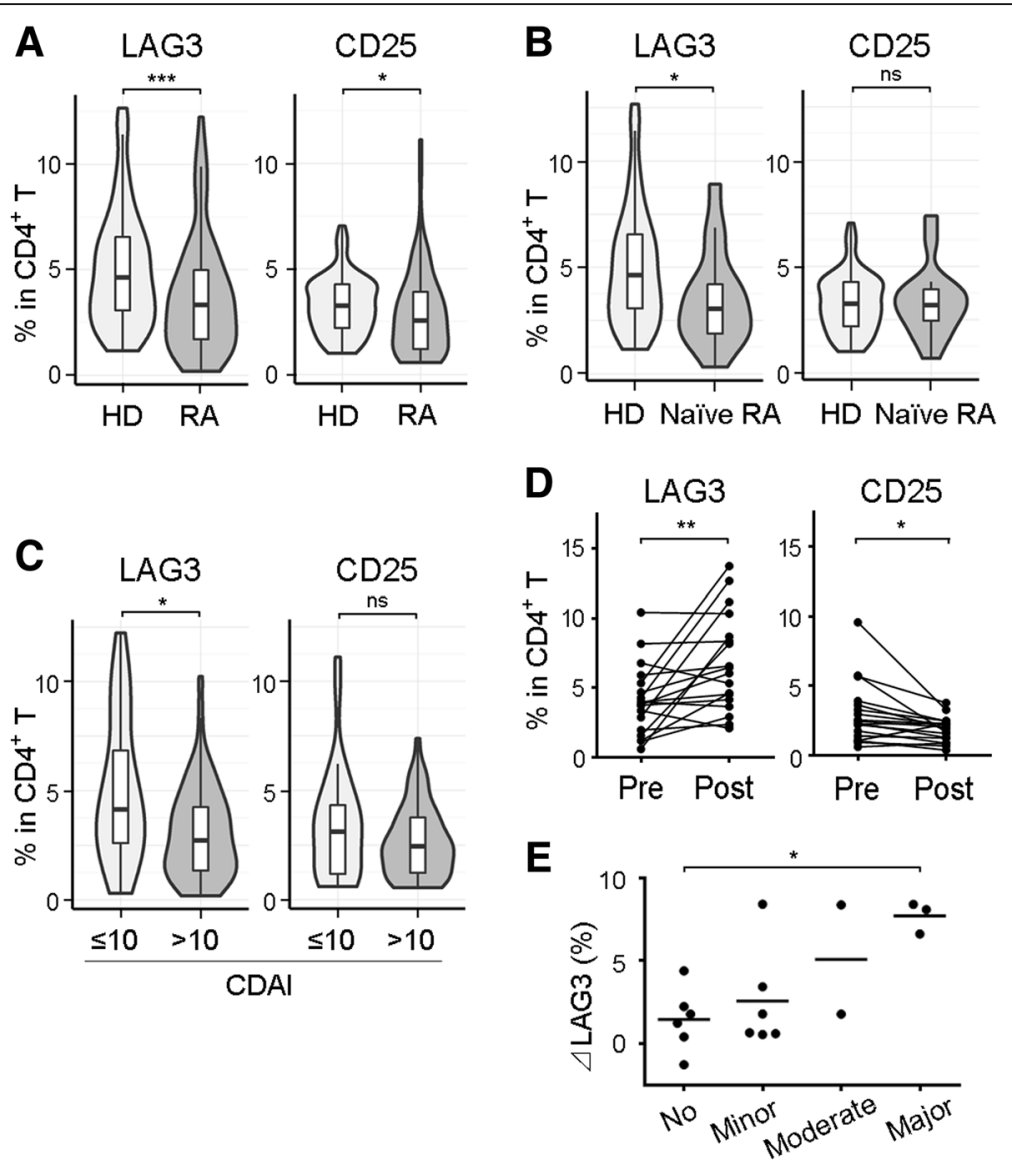

Fig. 3 Frequencies of $\mathrm{LAG}^{+}$Tregs and $\mathrm{CD} 25^{+}$Tregs in patients with RA and in healthy volunteers, as well as the effect of abatacept treatment. a and $\mathbf{b}$ PBMCs were taken from healthy donors (HD; $n=101)$ and patients with RA ( $n=85$, including 16 nontreated patients [naive RA]), and Treg subsets were assessed. c Patients with RA were divided into two groups according to Clinical Disease Activity Index (CDAl). Treg subsets were assessed (CDAl $\leq 10, n=30 ; \mathrm{CDAl}>10, n=55)$. $\mathbf{d}$ Treg subsets were analyzed immediately before and 6 months after abatacept treatment $(n=18)$. e Changes of percentages of $L A G 3^{+}$Tregs in $C D 4^{+} T$ cells $(\triangle \mathrm{LAG} 3)$ were evaluated in accordance with treatment response to abatacept $(n=18)$. No response was defined as less than 50\% improvement from baseline CDAI. Minor response was defined as at least a 50\% improvement from baseline CDAI. Moderate response was defined as at least a 70\% improvement from baseline CDAI. Major response was defined as at least an $85 \%$ improvement from baseline CDAl. ${ }^{*}, P<0.05$; ${ }^{*}, P<0.01$; ${ }^{* *}, P<0.001$. Statistics: (a-c) unpaired two-tailed Student's $t$ tests, (d) Wilcoxon signed-rank test, (e) Kruskal-Wallis test and Dunn's multiple-comparisons test. CD Cluster of differentiation, LAG3 Lymphocyte activation gene 3, ns Not significant, PBMC Peripheral blood mononuclear cell, RA Rheumatoid arthritis, Treg Regulatory T cell

between ACPA or rheumatoid factor (RF) titers and frequencies of $\mathrm{CD}_{2} 5^{+}$Tregs or LAG3 ${ }^{+}$Tregs (Additional file 1: Figure S4). To investigate the effect of RA treatment for LAG3 ${ }^{+}$Tregs, we focused on patients undergoing treatment with abatacept (Table 1). Abatacept treatment significantly increased the frequency of LAG3 ${ }^{+}$ Tregs and significantly decreased the frequency of CD25 $5^{+}$ Tregs (Fig. 3d). Moreover, we divided abatacept-treated patients into four groups (no response, minor response, moderate response, and major response) following the definition of treatment response based on Clinical Disease Activity Index $[25,26]$. We analyzed the correlation between treatment response and increase in $\mathrm{LAG}^{+}$Tregs and found that $\mathrm{LAG}^{+}$Tregs significantly increased in the patients with a major response to abatacept compared with the patients with no response (Fig. 3e). The same result was obtained from the analysis using the definition of treatment response based on Disease Activity Score in 28 joints based on erythrocyte sedimentation rate (Additional file 1: Figure S5). Taken together, LAG3 ${ }^{+}$ Tregs were present at a lower frequency in patients with RA than in healthy donors. Among patients with RA, the frequency of $\mathrm{LAG3}^{+}$Tregs was inversely correlated with disease activity. Moreover, abatacept increased the frequency of LAG3 ${ }^{+}$Tregs in patients with RA.

\section{Abatacept facilitates the differentiation of $\mathrm{LAG3}^{+}$ Treg-like cells}

Naive $\mathrm{CD}^{+} \mathrm{T}$ cells from healthy donors were cultured in the absence or presence of abatacept with irradiated APCs and anti-CD3 antibody for 4 days. When naive $\mathrm{CD} 4^{+} \mathrm{T}$ cells were cultured with abatacept, $\mathrm{CD} 4^{+} \mathrm{CD} 25$ 
${ }^{-} \mathrm{LAG}^{+} \mathrm{T}$ cells were more strongly induced than naive $\mathrm{CD}^{+} \mathrm{T}$ cells cultured without abatacept $(P<0.0001)$ (Fig. 4a). In contrast, the CD4 ${ }^{+} \mathrm{T}$ cells expressing CD25 decreased in the presence of abatacept (Fig. 4a). Moreover, the expression levels of EGR2 and FAS were increased in the abatacept-treated group $(P<0.01)$ (Fig. $4 \mathrm{~b})$. The expression of $C D 274$ (programmed death-ligand 1 [PD-L1]) had a tendency to increase in the abatacept-treated group. Egr2 is a key transcription factor that regulates LAG3 $^{+}$ Tregs [21]. Both Fas [23] and PD-L1 [27] were reported to be involved in $\mathrm{LAG}^{+}$Treg suppression ability. Furthermore, abatacept-induced CD $4^{+} \mathrm{T}$ cells significantly suppressed antibody production compared with the positive control $(P<0.0001)$ (Fig. $4 \mathrm{c})$. Taken together, these results indicated that abatacept facilitated the differentiation of Egr2-expressing $\mathrm{LAG}^{+}{ }^{+}$Treg-like cells from naive CD $4^{+} \mathrm{T}$ cells.

\section{Active immunization increases Th1 cells and decreases} LAG3 $^{+}$Tregs

At this point, it was possible that immunological stimulation in RA may have contributed to the decrease of LAG3 $^{+}$Tregs. We addressed whether LAG3 ${ }^{+}$Tregs exhibited numerical alteration in response to active immunization. Vaccination triggers an immune response in human bodies, preparing Th1 cells and memory B cells to respond quickly to previously encountered antigens. To investigate whether LAG3 ${ }^{+}$Tregs were affected by an immune response against foreign antigens, we inoculated four healthy subjects with seasonal influenza vaccine, which is a hemagglutinin fraction of influenza virus mixed strains grown in fertilized chicken eggs without adjuvant, and evaluated T-cell subsets in PBMCs at days 0,7 , and 14 . All four subjects showed an increase in the frequency of Th1 cells and a reciprocal decrease

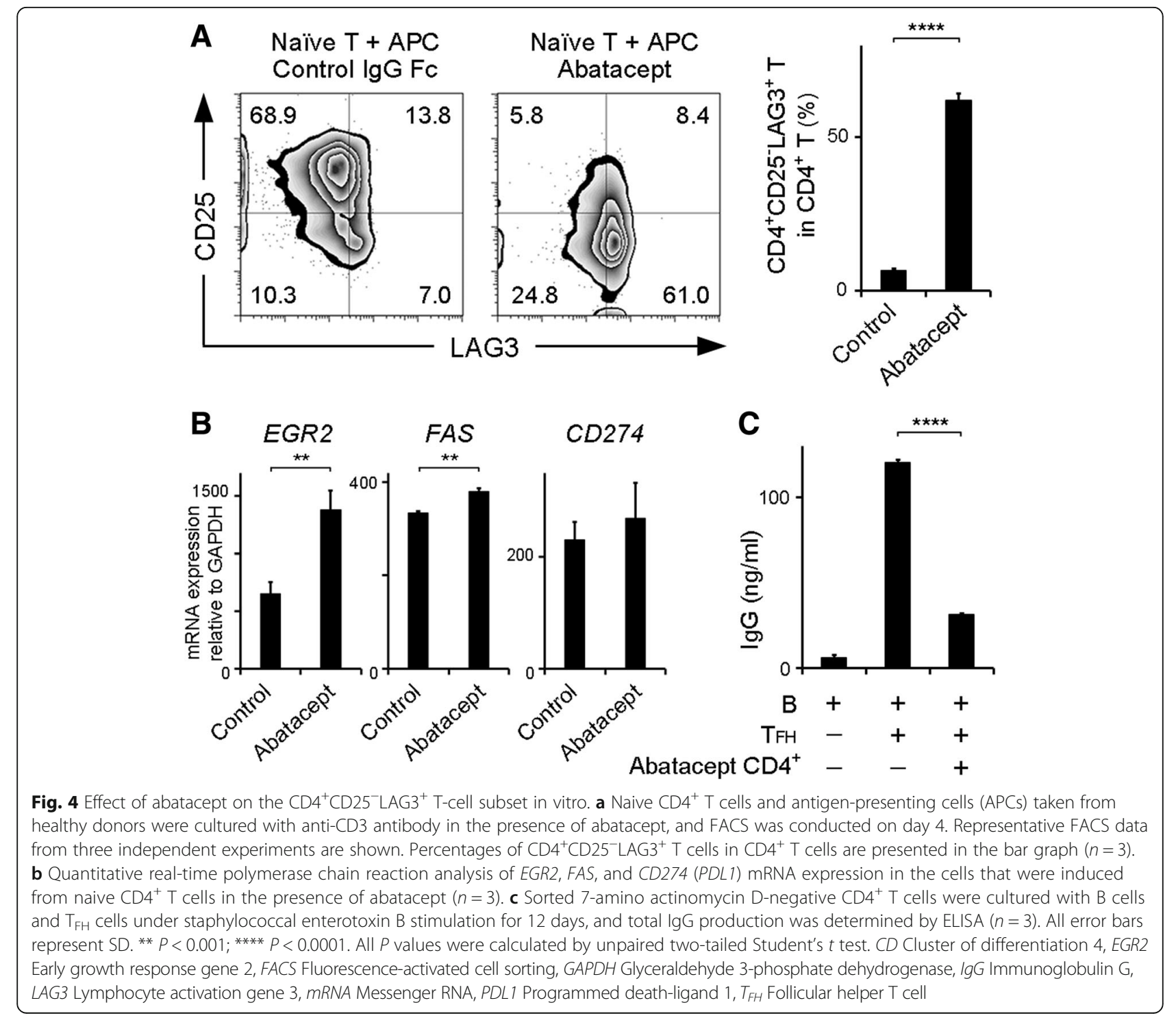


in that of $\mathrm{LAG}^{+}$Tregs at day 7. Both Th1 cells and LAG3 $^{+}$Tregs recovered their baseline percentages at day 14 (Fig. 5). In a former report, influenza vaccine administration did not influence the number of total CD4 $4^{+}$ $\mathrm{CD} 25^{+} \mathrm{T}$ cells, and it was supposed that the response to vaccine depends on the activation of different subsets of $\mathrm{CD} 4{ }^{+} \mathrm{CD} 25^{+} \mathrm{T}$ cells [28]. Active immunization may reduce the frequency of $\mathrm{LAG}^{+}$Tregs and increase that of Th1 cells to enhance immune responses.

\section{Discussion}

We detected the human counterpart of murine LAG3 $^{+}$ Tregs [23] that produce high amounts of IL-10 and IFN- $\gamma$ and strongly suppress B-cell antibody production. Although there are several reports stating that $\mathrm{T}$ cells suppress B-cell antibody production, most of them are related to $\mathrm{CD} 25^{+}$Tregs [29-31]. We found that human $\mathrm{LAG}^{+}$Tregs suppress B-cell antibody production more strongly than $\mathrm{CD} 25^{+}$Tregs. On one hand, an experiment using Transwell plates revealed that cell-tocell contact played a great role in B-cell suppression by $\mathrm{LAG3}^{+}$Tregs and that Fas-Fas ligand interaction might be involved in the mechanism. On the other hand, because $\mathrm{LAG}^{+}$Tregs suppressed B-cell antibody production to a certain extent even if they were separated from $\mathrm{B}$ and $\mathrm{T}_{\mathrm{FH}}$ cells, it is difficult to deny the effect of some cytokines. One possible cytokine is transforming growth factor (TGF)- $\beta 3$ because it is highly expressed in human $\mathrm{LAG}^{+}$Tregs, and murine LAG3 ${ }^{+}$Tregs directly suppress B-cell activation through TGF- $\beta 3$ [23].
Regardless of $\mathrm{CD} 49 \mathrm{~b}$ expression, $\mathrm{LAG}^{+}$cells produced high amounts of IL-10 and suppressed B-cell antibody production, although Gagliani et al. concluded that coexpression of LAG3 and CD49b was necessary to identify human IL-10-producing T cells [22]. The difference may be due to the very low frequency of $\mathrm{CD} 4^{+}$ CD $25^{-}$LAG3 $^{+} \mathrm{CD} 49 \mathrm{~b}^{+} \mathrm{T}$ cells observed in our study. Although the role of $\mathrm{CD} 49 \mathrm{~b}$ should be investigated further, our results confirmed that LAG3 is a unique marker for IL-10-producing $\mathrm{CD} 4^{+} \mathrm{T}$ cells.

On one hand, in the patients with untreated RA, the frequency of $\mathrm{CD} 25^{+}$Tregs was not different from that observed in healthy donors, consistent with previous reports [32-34]. On the other hand, the frequency of $\mathrm{LAG}^{+}$Tregs was significantly lower in patients with RA than in healthy donors, and it was particularly low in patients with RA with higher disease activity. These results imply that $\mathrm{LAG}^{+}$Tregs are involved in regulating the pathophysiology of RA. Among several possible mechanisms, one is suppression of B-cell functions. Autoreactive $\mathrm{B}$ cells not only produce autoantibody that can potentiate immune responses but also can directly interact with $T$ cells by antigen presentation, leading to cytokine production and germinal center formation [1,35]. A pathogenic role for $\mathrm{B}$ cells other than antibody production was confirmed by the efficacy of rituximab with limited reduction of ACPA titers in RA [36]. The other possibility is that $\mathrm{LAG3}^{+}$Tregs regulate RA via IL-10 production. IL-10-producing Tregs ameliorate collageninduced arthritis in mice [37]. Moreover, Th17 cells play
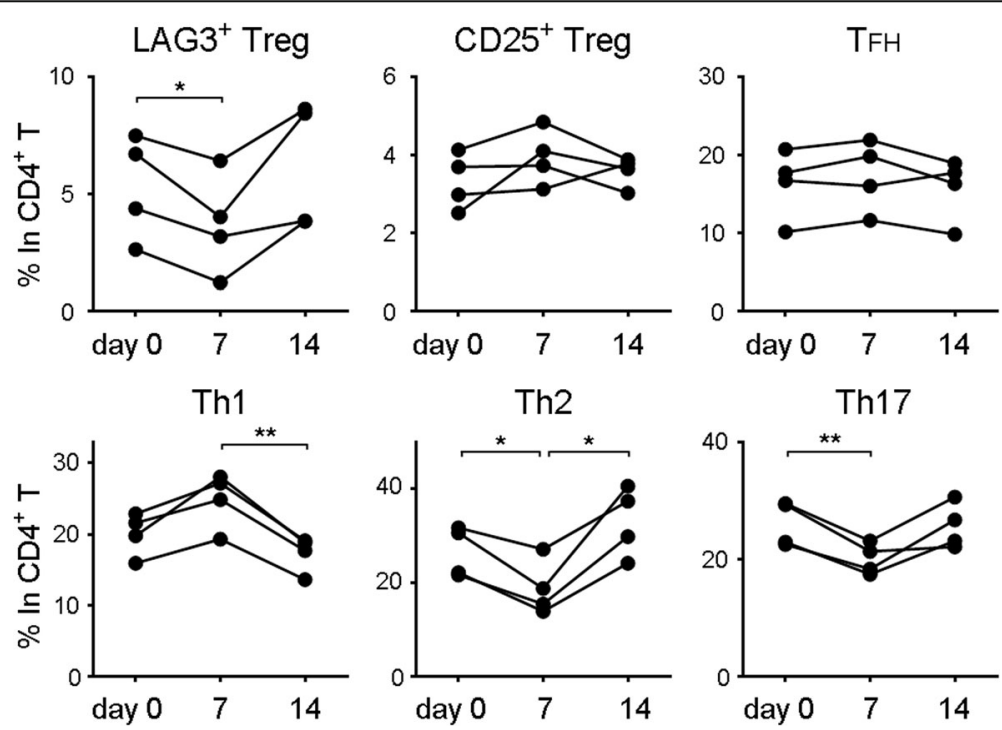

Fig. 5 Successive changes of $\mathrm{CD} 4^{+}$T-cell subsets after vaccination. Four healthy donors were inoculated with influenza vaccine. The indicated T-cell subsets were evaluated on day 0 (before vaccination), day 7 , and day $14 .{ }^{*} P<0.05$; ${ }^{* *} P<0.01$. $P$ values were calculated by one-way analysis of variance and Tukey's multiple-comparisons test. CD Cluster of differentiation, LAG3 Lymphocyte activation gene 3, ns Not significant, $T_{F H}$ Follicular helper T cell, Th Helper T cell, Treg Regulatory T cell 
crucial roles in the development of RA [38], and IL-10producing Tregs control inflammation by Th17 cells in an IL-10-dependent manner [39].

Administration of the costimulatory inhibitor abatacept significantly increased the frequency of $\mathrm{LAG}^{+}$Tregs in patients with RA. Moreover, naive $\mathrm{CD} 4^{+} \mathrm{T}$ cells stimulated in the presence of abatacept developed into $\mathrm{CD} 4^{+} \mathrm{T}$ cells with LAG3 ${ }^{+}$Treg-like manifestations. Although it is difficult to confirm the relationship between abatacept and $\mathrm{LAG}^{+}$Tregs, the expression of EGR2 strongly suggests the induction of LAG3 ${ }^{+}$Treg-like cells. The transcription factor EGR2 is identified as a T-cell anergy-associated gene [24] that is induced by TCR stimulation in the absence of costimulation. Moreover, EGR2 is highly expressed in both murine and human $\mathrm{LAG}^{+}$Tregs $[21,23]$. Because abatacept binds to $B 7$ molecules on APCs and inhibits T-cell costimulation [40], there is a possibility that abatacept enhances EGR2 expression by $\mathrm{CD}^{+}{ }^{+} \mathrm{T}$ cells and increases the number of $\mathrm{LAG}^{+}$ Tregs. Moreover, there was a significant increase in FAS expression and the tendency of CD274 (PDL1) expression to increase in the abatacept-treated cells. Because Fas [23] and PD-L1 [27] were reported to play a role in the suppression ability of LAG3 ${ }^{+}$Tregs, there is a possibility that abatacept-treated cells exert suppressive ability using FAS or PD-L1 in the same way as naturally occurring LAG3 ${ }^{+}$Tregs.

Immunological stimulation such as autoimmunity and vaccination may reduce the number of $\mathrm{LAG}^{+}$Tregs via costimulation. $\mathrm{LAG}^{+}$Tregs could participate in the antiinflammatory and immune-modulating effects achieved by a targeting therapy for costimulation. Actually, abatacept administration in patients with RA reduced the serum levels of immunoglobulins, ACPA, and RF as well as the percentage of postswitch memory B cells [41]. Increases in $\mathrm{LAG}^{+}$Tregs by abatacept treatment may be associated with control of humoral immunity. The fact that abatacept induces a general decrease of $\mathrm{CD} 25^{+}$Tregs is not consistent with the clinical efficacy of abatacept [42]. Increases of $\mathrm{LAG3}^{+}$Tregs may compensate for the reduction of $\mathrm{CD} 25^{+}$Tregs in abatacept-treated patients.

With regard to the mechanisms of the suppressive ability of $\mathrm{LAG}^{+}$Tregs, multiple systems have been reported to be involved. In the present study, we revealed the importance of cell-cell contact and Fas. In vivo experiments using Fas-mutant B6/lpr mice confirmed that Fas expressed on $\mathrm{LAG}^{+}$Tregs plays a critical role in suppressing B-cell antibody production [23], and our results suggest that Fas could contribute to LAG3 ${ }^{+}$Treg suppressive ability in humans. However, our Transwell experiment also suggested that soluble factors have some effect because LAG3 ${ }^{+}$Treg suppression was still observed even if cell-to-cell contact was lost. One candidate is TGF- $\beta 3$, which is highly expressed by both murine and human LAG3 ${ }^{+}$Tregs [43]. In vivo experiments confirmed that TGF- $\beta 3$ strongly ameliorates B-cell-mediated pathology [23] and that TGF- $\beta 3$ suppresses human B-cell differentiation into plasmablasts and antibody secretion [44]. We suppose that multiple mechanisms, including soluble factors (IL-10, TGF- $\beta 3$ ) and cell-to-cell contact (PD-L1 and Fas), work together in bringing about LAG3 $^{+}$Treg suppression.

In a previous report, Egr2-transduced $\mathrm{LAG}^{+}{ }^{+}$Treglike $\mathrm{CD}^{+} \mathrm{T}$ cells exhibited antigen-specific immunosuppressive capacity in vivo. On the basis of these findings, human $\mathrm{LAG}^{+}$Tregs are supposed to be specific to selfantigens associated with autoimmune disease; however, proving antigen specificity in human Tregs is difficult and remains to be elucidated.

Collectively, the results of our study suggest that human IL-10-producing-LAG3 ${ }^{+}$Tregs regulate immune responses related to the pathogenesis of RA. The induction of $\mathrm{LAG3}^{+}$Tregs by abatacept implies a previously unrecognized role of IL-10-producing Tregs in the mode of action of abatacept.

\section{Conclusions}

IL-10-producing LAG3 ${ }^{+}$Tregs in human PBMCs suppress the antibody production of $\mathrm{B}$ cells independent of IL-10. The frequency of $\mathrm{LAG}^{+}$Tregs is decreased in patients with RA and significantly increased with abatacept treatment. Abatacept-treated $\mathrm{CD}^{+} \mathrm{T}$ cells exhibit LAG3 $^{+}$Treg-like function.

\section{Additional file}

\begin{abstract}
Additional file 1: Supplementary methods and figures. Figure S1 Expression of FOXP3 in $\mathrm{LAG}^{+}$Tregs and $\mathrm{CD} 25^{+}$Tregs. Freshly isolated human $\mathrm{CD}^{+} \mathrm{T}$ cells were stained for FOXP3 and LAG3. Representative FACS data from three independent experiments are shown. Figure S2 In vitro T-cell proliferation assay. Carboxyfluorescein succinimidyl esterlabeled naive T cells were cultured with irradiated APCs and CD25 ${ }^{+}$Tregs for $72 \mathrm{~h}$. Representative FACS data from three independent experiments are shown. Figure S3 Frequencies of $1 \mathrm{~L}-10^{+}$cells in 7-AAD- cells detected in intracellular staining of naive $\mathrm{CD} 4^{+} \mathrm{T}$ cells and $\mathrm{LAG} 3^{+}$Tregs $(n=4)$. * $P<0.05$ by Mann-Whitney $U$ test. Figure S4 Scatterplot of frequencies of $\mathrm{CD}_{2} 5^{+}$Tregs or $\mathrm{LAG3}^{+}$Tregs vs ACPA titer or RF $(n=83)$. $P$ value is for Spearman's rank correlation coefficient. rho Spearman's rho. Linear regression line is drawn as a blue line, and $95 \% \mathrm{Cl}$ region is presented as a gray area. a Scatterplot of frequencies of CD $25^{+}$Tregs vs ACPA titer. $\mathbf{b}$ Scatterplot of frequencies of $C D 25^{+}$Tregs vs RF titer. c Scatterplot of frequencies of $\mathrm{LAG}^{+}$ Tregs vs ACPA titer. $\mathbf{d}$ Scatterplot of frequencies of $L A G 3^{+}$Tregs vs RF titer. Figure S5 Changes in percentages of $\mathrm{LAG}^{+}$Tregs in $\mathrm{CD} 4^{+} \mathrm{T}$ cells $(\Delta \mathrm{LAG} 3$ ) were evaluated in accordance with treatment response to abatacept $(n=18)$. Patients were divided into three groups (no response, moderate response, and good response) following European League Against Rheumatism response criteria based on DAS28-ESR. ${ }^{*} P<0.05$ by Kruskal-Wallis test and Dunn's multiple-comparisons test. (ZIP $963 \mathrm{~kb}$ )
\end{abstract}

\section{Abbreviations}

7-AAD: 7-Amino actinomycin D; Ab: Antibody; ACPA: Anticitrullinated protein antibody; APC: Antigen-presenting cell; CCP: Cyclic citrullinated peptide; CCR6: C-C chemokine receptor type 6; CCR7: C-C chemokine receptor type 7; CD: Cluster of differentiation; CDAl: Clinical Disease Activity Index; 
CRP: C-reactive protein; CXCR3: C-X-C chemokine receptor type 3; CXCR5: C$X-C$ chemokine receptor type 5; DAS28: Disease Activity Score in 28 joints; Egr2: Early growth response gene 2; ELISA: Enzyme-linked immunosorbent assay; ESR: Erythrocyte sedimentation rate; FACS: Fluorescence-activated cell sorting; FasL: Fas ligand; Foxp3: Forkhead box P3; GAPDH: Glyceraldehyde 3-phosphate dehydrogenase; HD: Healthy donor; IFN- $\gamma$ : Interferon- $\gamma$; Ig: Immunoglobulin; IL: Interleukin; LAG3: Lymphocyte activation gene 3; mAb: Monoclonal antibody; mRNA: Messenger RNA; MTX: Methotrexate; PBMC: Peripheral blood mononuclear cell; PCR: Polymerase chain reaction; PD-L1: Programmed death-ligand 1; PE: Phycoerythrin; PerCP: Peridininchlorophyll protein; RA: Rheumatoid arthritis; RF: Rheumatoid factor; RPMI: Roswell Park Memorial Institute medium; SEB: Staphylococcal enterotoxin B; TCR: T-cell receptor; $T_{F H}$ : Follicular helper T cell; TGF- $\beta$ : Transforming growth factor- $\beta$; Th1: Type 1 helper $T$ cell; Th17: T helper 17 cell; TNF-a: Tumor necrosis factor-a; Treg: Regulatory $T$ cell

\section{Acknowledgements}

We thank the patients and healthy volunteers who participated in this research. We thank K. Watada, J. Takezawa, A. Inoue, and M. Anraku for their excellent technical assistance. We thank K. Kubo, H. Harada, M. Shibuya, Y. Iwasaki, K. Michishita, T. Eri, Y. Seri, and M. Ohshima for their help in collecting patients' data.

\section{Funding}

This work was supported by the Ministry of Health, Labour and Welfare, Ministry of Education, Culture, Sports, Science and Technology under a Grant-in-Aid for Scientific Research (KAKENHI) (S) (23229007), a Grant-in-Aid for challenging Exploratory Research (25670459), and a Grant-in-Aid for Young Scientists (B) (15 K19566) from the Japan Society for the Promotion of Science. Part of this work was supported by a grant from Bristol-Myers Squibb (BMKK130307).

\section{Authors' contributions}

SN, SS, YT, HT, MK, RK, TO, KY, and KF conceived of, designed, and analyzed the experiments and contributed to writing the manuscript. SN, $\mathrm{SS}$, and KF carried out all experiments. KS, NH, YN, ST, and HK helped with obtaining human samples and clinical data. All authors read and approved the final manuscript.

\section{Competing interests}

KY received financial support or fees from AbbVie, Astellas Pharma, Bristol-Myers Squibb, Daiichi-Sankyo, MitsubishiTanabe Pharma, Pfizer, Sanofi, Santen, Takeda, Teijin, Boehringer Ingelheim, Chugai, Eisai, Ono, Taisho Toyama, UCB, ImmunoFuture, Asahi Kasei, and Janssen. KF received financial support or fees from Astellas Pharma, Bristol-Myers Squibb, Daiichi-Sankyo, MitsubishiTanabe Pharma, Pfizer, Santen, Takeda, Chugai, Eisai, Taisho Toyama, UCB, and Janssen. SS received financial support or fees from AbbVie, Eisai, Chugai, Takeda, Bristol-Myers Squibb, and UCB. All other authors declare that they have no competing interests.

\section{Ethics approval and consent to participate}

All clinical investigations conformed to the Declaration of Helsinki principles and were approved (10154 and G3582) by the ethics committee of the University of Tokyo. Consent was obtained from all patients who participated in this study.

\section{Publisher's Note}

Springer Nature remains neutral with regard to jurisdictional claims in published maps and institutional affiliations.

\section{Author details}

${ }^{1}$ Department of Allergy and Rheumatology, Graduate School of Medicine, the University of Tokyo, 7-3-1 Hongo, Bunkyo-ku, Tokyo 113-8655, Japan. ${ }^{2}$ Department of Immunotherapy Management, Graduate School of Medicine, the University of Tokyo, 7-3-1 Hongo, Bunkyo-ku, Tokyo 113-8655, Japan. ${ }^{3}$ Max Planck-The University of Tokyo Center for Integrative Inflammology, The University of Tokyo, 4-6-1 Komaba, Meguro-ku, Tokyo 153-8505, Japan.
Received: 18 December 2016 Accepted: 2 May 2017 Published online: 16 May 2017

\section{References}

1. Smolen JS, Aletaha D, Redlich K. The pathogenesis of rheumatoid arthritis: new insights from old clinical data? Nat Rev Rheumatol. 2012;8:235-43.

2. Mclnnes IB, Schett $G$. The pathogenesis of rheumatoid arthritis. N Engl J Med. 2011;365:2205-19.

3. Esensten JH, Wofsy D, Bluestone JA. Regulatory T cells as therapeutic targets in rheumatoid arthritis. Nat Rev Rheumatol. 2009;5:560-5.

4. Roncarolo MG, Battaglia M. Regulatory T-cell immunotherapy for tolerance to self antigens and alloantigens in humans. Nat Rev Immunol. 2007;7:585-98.

5. Sakaguchi S, Yamaguchi T, Nomura T, Ono M. Regulatory T cells and immune tolerance. Cell. 2008;133:775-87.

6. Sakaguchi S, Sakaguchi N, Asano M, Itoh M, Toda M. Immunologic selftolerance maintained by activated $T$ cells expressing $\mathrm{IL}-2$ receptor a-chains (CD25): breakdown of a single mechanism of self-tolerance causes various autoimmune diseases. J Immunol. 1995;155:1151-64.

7. Groux H, O'Garra A, Bigler M, Rouleau M, Antonenko S, de Vries JE, et al. A CD4 ${ }^{+}$T-cell subset inhibits antigen-specific T-cell responses and prevents colitis. Nature. 1997;389:737-42.

8. Linterman MA, Pierson W, Lee SK, Kallies A, Kawamoto S, Rayner TF, et al. Foxp $3^{+}$follicular regulatory $T$ cells control the germinal center response. Nat Med. 2011;17:975-82.

9. Lim HW, Hillsamer P, Banham AH, Kim CH. Cutting edge: direct suppression of $B$ cells by $C D 4^{+} C D 25^{+}$regulatory T cells. J Immunol. 2005:175:4180-3.

10. Kim HJ, Verbinnen B, Tang X, Lu L, Cantor H. Inhibition of follicular T-helper cells by $\mathrm{CD}^{+}{ }^{+}$regulatory $T$ cells is essential for self tolerance. Nature. 2010;467:328-32

11. Hori S, Nomura T, Sakaguchi S. Control of regulatory T cell development by the transcription factor Foxp3. Science. 2003;299:1057-61.

12. Brunkow ME, Jeffery EW, Hjerrild KA, Paeper B, Clark LB, Yasayko SA, et al. Disruption of a new forkhead/winged-helix protein, scurfin, results in the fatal lymphoproliferative disorder of the scurfy mouse. Nat Genet. 2001;27:68-73.

13. Chen Z, Benoist C, Mathis D. How defects in central tolerance impinge on a deficiency in regulatory T cells. Proc Natl Acad Sci U S A. 2005;102:14735-40.

14. Fujio K, Okamura T, Yamamoto K. The family of IL-10-secreting $\mathrm{CD}^{+} \mathrm{T}$ cells. Adv Immunol. 2010;105:99-130.

15. Fitzgerald DC, Zhang GX, El-Behi M, Fonseca-Kelly Z, Li H, Yu S, et al. Suppression of autoimmune inflammation of the central nervous system by interleukin 10 secreted by interleukin 27-stimulated T cells. Nat Immunol. 2007:8:1372-9.

16. Barrat FJ, Cua DJ, Boonstra A, Richards DF, Crain C, Savelkoul HF, et al. In vitro generation of interleukin 10-producing regulatory $\mathrm{CD}^{+} \mathrm{T}$ cells is induced by immunosuppressive drugs and inhibited by $T$ helper type 1 (Th1)- and Th2-inducing cytokines. J Exp Med. 2002;195:603-16.

17. Kemper C, Chan AC, Green JM, Brett KA, Murphy KM, Atkinson JP. Activation of human $\mathrm{CD}^{+}$cells with CD3 and CD46 induces a T-regulatory cell 1 phenotype. Nature. 2003:421:388-92

18. Battaglia M, Stabilini A, Draghici E, Gregori S, Mocchetti C, Bonifacio E, et al. Rapamycin and interleukin-10 treatment induces $T$ regulatory type 1 cells that mediate antigen-specific transplantation tolerance. Diabetes. 2006:55:40-9.

19. Awasthi A, Carrier Y, Peron JP, Bettelli E, Kamanaka M, Flavell RA, et al. A dominant function for interleukin 27 in generating interleukin 10-producing anti-inflammatory T cells. Nat Immunol. 2007:8:1380-9.

20. Apetoh L, Quintana FJ, Pot C, Joller N, Xiao S, Kumar D, et al. The aryl hydrocarbon receptor interacts with c-Maf to promote the differentiation of type 1 regulatory T cells induced by IL-27. Nat Immunol. 2010;11:854-61.

21. Okamura T, Fujio K, Shibuya M, Sumitomo S, Shoda H, Sakaguchi S, Yamamoto $\mathrm{K} . \mathrm{CD}^{+} \mathrm{CD} 25^{-} \mathrm{LAG} 3^{+}$regulatory T cells controlled by the transcription factor Egr-2. Proc Natl Acad Sci U S A. 2009;106:13974-9.

22. Gagliani N, Magnani CF, Huber S, Gianolini ME, Pala M, Licona-Limon P, et al. Coexpression of CD49b and LAG-3 identifies human and mouse T regulatory type 1 cells. Nat Med. 2013;19:739-46.

23. Okamura T, Sumitomo S, Morita K, Iwasaki Y, Inoue M, Nakachi S, et al. TGF- $\beta 3$-expressing $C D 4^{+} \mathrm{CD} 25^{-} \mathrm{LAG}^{+}$regulatory $T$ cells control humoral immune responses. Nat Commun. 2015;6:6329.

24. Safford M, Collins S, Lutz MA, Allen A, Huang CT, Kowalski J, et al. Egr-2 and Egr-3 are negative regulators of T cell activation. Nat Immunol. 2005;6:472-80. 
25. Aletaha D, Martinez-Avila J, Kvien TK, Smolen JS. Definition of treatment response in rheumatoid arthritis based on the simplified and the clinical disease activity index. Ann Rheum Dis. 2012;71:1190-6.

26. Smolen JS, Aletaha D. Scores for all seasons: SDAl and CDAl. Clin Exp Rheumatol. 2014;32(5 Suppl 85):S75-9.

27. Sumitomo S, Nakachi S, Okamura T, Tsuchida Y, Kato R, Shoda H, et al. Identification of tonsillar $\mathrm{CD} 4^{+} \mathrm{CD} 25^{-} \mathrm{LAG} 3^{+} \mathrm{T}$ cells as naturally occurring IL-10-producing regulatory $T$ cells in human lymphoid tissue. J Autoimmun. 2017;76:75-84.

28. Del Porto F, Lagana B, Biselli R, Donatelli I, Campitelli L, Nisini R, et al. Influenza vaccine administration in patients with systemic lupus erythematosus and rheumatoid arthritis: safety and immunogenicity. Vaccine. 2006;24:3217-23.

29. Gotot J, Gottschalk C, Leopold S, Knolle PA, Yagita H, Kurts C, et al. Regulatory T cells use programmed death 1 ligands to directly suppress autoreactive $B$ cells in vivo. Proc Natl Acad Sci U S A. 2012;109:10468-73.

30. likuni $\mathrm{N}$, Lourenco EV, Hahn BH, La Cava A. Cutting edge: regulatory T cells directly suppress B cells in systemic lupus erythematosus. J Immunol. 2009;183:1518-22.

31. Zhao DM, Thornton AM, DiPaolo RJ, Shevach EM. Activated $C D 4^{+} C D 25^{+} T$ cells selectively kill B lymphocytes. Blood. 2006;107:3925-32.

32. Mottonen $M$, Heikkinen J, Mustonen L, Isomaki P, Luukkainen R, Lassila O. $\mathrm{CD} 4^{+} \mathrm{CD} 25^{+} \mathrm{T}$ cells with the phenotypic and functional characteristics of regulatory $T$ cells are enriched in the synovial fluid of patients with rheumatoid arthritis. Clin Exp Immunol. 2005;140:360-7.

33. Ehrenstein MR, Evans JG, Singh A, Moore S, Warnes G, Isenberg DA, et al. Compromised function of regulatory $T$ cells in rheumatoid arthritis and reversal by anti-TNFa therapy. J Exp Med. 2004;200:277-85.

34. Cao D, Malmstrom V, Baecher-Allan C, Hafler D, Klareskog L, Trollmo C. Isolation and functional characterization of regulatory CD25 $5^{\text {bright }} \mathrm{CD} 4^{+} \mathrm{T}$ cells from the target organ of patients with rheumatoid arthritis. Eur J Immunol. 2003;33:215-23.

35. Byng-Maddick R, Ehrenstein MR. The impact of biological therapy on regulatory $T$ cells in rheumatoid arthritis. Rheumatology (Oxford). 2015:54:768-75.

36. Edwards JC, Szczepanski L, Szechinski J, Filipowicz-Sosnowska A, Emery P, Close DR, et al. Efficacy of B-cell-targeted therapy with rituximab in patients with rheumatoid arthritis. N Engl J Med. 2004;350:2572-81.

37. Asnagli H, Martire D, Belmonte N, Quentin J, Bastian H, Boucard-Jourdin M, et al. Type 1 regulatory $T$ cells specific for collagen type II as an efficient cell-based therapy in arthritis. Arthritis Res Ther. 2014;16:R115.

38. Leipe J, Grunke M, Dechant C, Reindl C, Kerzendorf U, Schulze-Koops H, et al. Role of Th17 cells in human autoimmune arthritis. Arthritis Rheum. 2010;62:2876-85

39. Huber S, Gagliani N, Esplugues E, O'Connor Jr W, Huber FJ, Chaudhry A, et al. Th17 cells express interleukin-10 receptor and are controlled by Foxp3- and Foxp3 ${ }^{+}$regulatory CD4 ${ }^{+} \mathrm{T}$ cells in an interleukin-10-dependent manner. Immunity. 2011:34:554-65.

40. Fiocco U, Sfriso P, Oliviero F, Pagnin E, Scagliori E, Campana C, et al. Co-stimulatory modulation in rheumatoid arthritis: the role of (CTLA4-Ig) abatacept. Autoimmun Rev. 2008;8:76-82.

41. Scarsi M, Paolini L, Ricotta D, Pedrini A, Piantoni S, Caimi L, et al. Abatacept reduces levels of switched memory B cells, autoantibodies, and immunoglobulins in patients with rheumatoid arthritis. J Rheumatol. 2014:41:666-72

42. Pieper J, Herrath J, Raghavan S, Muhammad K, Vollenhoven R, Malmstrom V. CTLA4-lg (abatacept) therapy modulates $T$ cell effector functions in autoantibody-positive rheumatoid arthritis patients. BMC Immunol. 2013;14:34.

43. Morita K, Okamura T, Inoue M, Komai T, Teruya S, Iwasaki Y, et al. Egr2 and Egr3 in regulatory $T$ cells cooperatively control systemic autoimmunity through Ltbp3-mediated TGF- $\beta 3$ production. Proc Natl Acad Sci U S A. 2016;113:E8131-40.

44. Tsuchida Y, Sumitomo S, Ishigaki K, Suzuki A, Kochi Y, Tsuchiya H, et al. TGF- $\beta 3$ inhibits antibody production by human B cells. PLoS One. 2017;12, e0169646.

\section{Submit your next manuscript to BioMed Central and we will help you at every step:}

- We accept pre-submission inquiries

- Our selector tool helps you to find the most relevant journal

- We provide round the clock customer support

- Convenient online submission

- Thorough peer review

- Inclusion in PubMed and all major indexing services

- Maximum visibility for your research

Submit your manuscript at www.biomedcentral.com/submit

) Biomed Central 